\section{Functional limitations of Brazilian elderly by age and gender differences: data from SABE Survey}

\author{
Diferenças em limitações funcionais \\ de idosos brasileiros de acordo com idade \\ e sexo: dados da pesquisa SABE
}

Aline R. Barbosa ${ }^{1,2}$
José M. P. Souza ${ }^{3}$
Maria L. Lebrão ${ }^{3}$
Ruy Laurenti ${ }^{3}$
Maria de Fátima N. Marucci ${ }^{3}$

\section{Introduction}

This study provides the prevalence, by gender and age-groups, of observed physical performance test (PPT) assessing functional limitation for representative samples of elderly Brazilian subjects living in São Paulo city. This crosssectional epidemiological study, both population-and household-based, is part of a multicenter survey (SABE) undertaken in seven Latin American and Caribbean countries and coordinated by the Pan-American Health Organization. From January 2000 to March 2001, 2,143 elderly individuals ( $\geq 60$ years) of both sexes were examined. Of this total, 1,894 participated in the study. PPT included handgrip strength, standing balance, timed repeated "chair stand", and "pick up a pen". Results have shown (based on chi-square) that the prevalence relating to the performance differed according to sex, age group, and from one test to another. With increasing age, there was a reduction $(p=0.000)$ in both males and females in the proportion of individuals that had better results on the tests. The male group, on every test, when compared to women from the same age group, had a more individuals with better scores. Data suggest that older individuals and women have more functional limitations.

Aging Health; Aging; Hand Strength; Time and Motion Studies
Rapid growth in the number of elderly people and increasing life expectancy have been reported in Brazil and other Latin American and Caribbean countries, making the knowledge of how well these individuals live extremely important, in order for public health policies to be planned according to the real needs of senior citizens.

Along with the usual health information related to chronic diseases, data on elderly people's functional capacity (neural-musculoskeletal) can elucidate issues pertaining to their well-being and quality of life, concerning the factors involved in their ability to maintain independent living 1,2,3.

Functional limitations can be assessed through self-reporting or physical performance tests (PPT). PPT checks the difficulty in performing given activities and is considered capable of identifying the physical parameters involved in performing daily tasks 3,4 .

In Brazil, information on health conditions of elderly people ( $\geq 60$ years) is still insufficient, and no epidemiological study using motor performance tests for functional evaluation of the elderly has been found in the literature. This project presents the prevalence, according to sex and age groups, of motor performance tests that evaluated hand-grip strength and some functions related to lower limbs, for elderly people from the city of São Paulo. 


\section{Methods}

This is a cross-sectional household-based epidemiological study which is part of the Survey on Health and Well-being of Elders (SABE - in Brazil, Saúde, Bem-estar e Envelhecimento), a multicenter study, coordinated by Pan-American Health Organization (PAHO), carried out in seven countries of Latin America and the Caribbean (Argentina, Barbados, Chile, Cuba, Mexico, Uruguay, and Brazil). In Brazil, the study was conducted in the city of São Paulo and coordinated by faculty members from the School of Public Health, University of São Paulo.

The research questionnaire designed by PA$\mathrm{HO}$ and translated and adapted for application in Brazil. Data were collected in two stages. The first was a household interview, done by just one interviewer, covering several questions on living conditions and health status of the elderly; the second was a household visit by a pair of interviewers, including anthropometric and physical performance measurements.

The study population consisted of individuals aged 60 years and older, of both sexes, residing in São Paulo city, during 2000 and the first quarter of 2001 (data collection). In the first phase of the research 2,143 individuals were interviewed, and in the second phase the measurements of 1,894 (88.4\%) elderly were taken. The main reasons for non-participation in this phase of the study were: refusal $(7.5 \%)$; address change $(2.0 \%)$; death $(1.9 \%)$; committed to an institution $(0.1 \%)$ and hospitalized $(0.1 \%)$.

The sampling process consisted of two segments: the first corresponding to the probabilistic sample, composed of 1,568 individuals, stratified by sex and age group, using for the household a draw method of sampling by grouping, in two stages, using the criterion of division in proportion to the size of the sample. The second consisted of 575 individuals, corresponding to the enlarged sample (of free composition) of the 75-year-and-older age group, for both sexes, because of the lower population density in this age group, and was adjusted for the male sex in relation to the female to offset the higher death-rate among the former 5 .

The study was approved by the Research Ethics Committee at the School of Public Health, University of São Paulo, and by the National Committee for Research Ethics (CONEP). Participation was voluntary, and a signed informed consent form was obtained.

\section{Physical performance tests}

Data were obtained by health professionals and graduate students from the nutrition course, who received special training in which a videotape prepared by the National Institute of $\mathrm{Nu}^{-}$ trition of the University of Chile was used, for standardization and better visual presentation of the techniques to be used for PPT.

PPTs for this study were administered by two interviewers in a home setting with limited unobstructed space. The dimensions assessed by the PPT included: upper body strength, lower body strength, mobility/flexibility, and balance.

The individuals that refused to take the tests or were unable to understand the instructions due to any cognitive problems were excluded from the analyses. Individuals unable to perform the maneuvers because of physical limitations were included in the data: those who could not walk or needed help to keep standing, had paralysis on any extremity, had a prosthesis on either leg, or could not keep balance did not take the tests related to the lower limbs; those who had undergone eye surgery during the previous six weeks did not take a "pick up a pen" test; individuals who had undergone arm or hand surgery in the three months prior to data collection did not take a handgrip strength test.

Before each test, one of the interviewers explained and demonstrated the task and made sure that the task could be completed without any physical risk to the subject.

A handgrip dynamometer (Takey Kiki Kogyio TK 1201, Japan) was used to assess upper body strength. The test was taken using the arm that the subject considered dominant. During the test, the subject remained sitting, with the elbow on a table, the forearm pointing forward, and the palm of the hand facing up, and attempted to make the strongest grip possible. Two trials, with a brief pause ( 1 minute) were allowed for each hand grip, and the highest number was recorded (in $\mathrm{kg}$ ). Individuals were encouraged to exert their maximal grip. To evaluate the performance in this test, distribution of the numbers $(\mathrm{kg})$ was made in percentiles, according to gender. They were classified according to the following score: unable, score 0 ; $\leq 25$ th, score 1 (poor); $>25$ th to $\leq 75$ th, score 2 (average); > 75th, score 3 (very good).

The test called "chair stands" was used to assess lower body strength. Before the test it was determined that the subject first performed five chair stands so that it would be safe for the participants to stand up from an armless chair without using their arms. Following the success- 
ful completion of the task, participants were asked to fold their arms across their chests and stand up and sit down five times as quickly as possible, and were timed from the initial sitting position to the final standing position, at the end of the fifth stand. This test was considered to be successfully accomplished when completed in $\leq 60$ seconds. Quartiles for the length of time required for this measure were used for scoring. Performance categories were created to permit analyses that included those unable to perform the task, as follows: $>60$ seconds, score 0 (unable); $>16$ to $\leq 60$ seconds, score 1 (poor); $>10$ to $\leq 16$ seconds, score 2 (average); $\leq 10$ seconds, score 3 (very good).

The test termed "pick up a pen" 6 was used to verify mobility/flexibility. For this task the participants were asked to attempt to remain standing with their feet side-by-side and, when told that the test had started, they were supposed to bend down to pick up a pen, which was put $30 \mathrm{~cm}$ ahead of their feet, on the floor. The subjects were timed from the initial standing position to the final standing position after picking up the pen. The test was considered complete when it was performed without any support in $\leq 30$ seconds. The classification used for this test was adapted from Reuben \& Siu 6 , with a four-mark scale (0-3), and included those unable to perform the task, as follows: $>30 \mathrm{sec}-$ onds, score 0 (unable); $>6$ to $\leq 30$ seconds, score 1 (poor); $>2$ to $\leq 6$ seconds, score 2 (average); $\leq 2$ seconds, score 3 (very good).

Balance was determined by four separate measurements. The subject was asked to perform each of the following tasks for 10 seconds: (1) maintain balance with both feet together and touching (side-by-side stand); (2) maintain balance when standing with the heel of one foot directly in front of the toes of the other foot (full tandem stand); (3) maintain balance when standing only on the right leg (one-leg stand); (4) maintain balance when standing only on the left leg (one-leg stand). The subjects were given a score of 0 (unable) if they were unable to perform any of the tasks for 10 seconds; a score of 1 (poor) if they could hold a side-by-side standing position for 10 seconds but were unable to do any other task; a score of 2 (average) if they could hold a side-by-side standing position and full tandem stand for 10 seconds each, but were unable to do a one-leg stand (right and left); a score of 3 (very good) if they could hold a one-leg standing position (right, left, or both).

\section{Statistical procedure}

The means, standard errors, and percentiles (10, $25,50,75,90)$, were used in accordance with the sex and age group (60-69, 70-79, $\geq 80$ years) for data analysis. Determination of the differences between means was made with Student's $t$-test ( $\mathrm{p} \leq 0.05$ ) for the comparison between sexes; the effect of age group was assessed by ANOVA ( $\mathrm{p} \leq 0.05)$. Cross-tabulation with $\chi^{2}$ test (Pearson chi-square, $\mathrm{p} \leq 0.05$ ) was used to verify the proportion of those unable to perform the test and with poor, average, and very good performance in each test, by sex and age group. All statistical analyses were carried out using SPSS, Base 8.0.

\section{Results}

The sample ranged in age from 60 to 100 years $(74.24 \pm 8.44) ; 37.2 \%$ of the sample was aged $60-69$ years, $38.6 \%$ 70-79 years, and $24.2 \%$ over 80 years.

From a total of 1,894 elderly analyzed, $0.2 \%$ (8) and $4.1 \%$ (78), for handgrip strength and lower extremity function tests, respectively, were unable to understand the instructions (and individuals that refused to take the tests) and hence were not included in the analysis. Individuals with physical limitations preventing them from performing the tests were included in the data, with a score of zero (unable) for each test.

The times for the repeated "chair stand" and "pick up a pen", by gender and age group are shown in Table 1. Mean times $( \pm$ standard error) for women to perform the test were significantly longer ( $p=0.000$ ) than for men in repeat "chair stands" in all age groups. This was also true for the "pick up a pen" test, except for the $\geq 80$ year-old age group, in which there was no difference $(p>0.05)$ in mean times for men and women. For both genders, the time needed to do the tasks ("chair stands" and "pick up a pen") increased with age $(p=0.000)$, with the greatest time required by over- 80 seniors.

For the handgrip strength (Table 1) men presented higher values (means $\pm \mathrm{SE}$ ) than women, the differences being significant $(p=0.000)$ in all age groups. The reduction of grip strength with advancing age, for both genders, was significant $(\mathrm{p}=0.000)$. When the oldest age group was compared to the 60-69-year age group the reduction in handgrip strength (median) was $36.7 \%(8 \mathrm{~kg})$ and $30.6 \%(11 \mathrm{~kg})$ for women and men, respectively (Table 2 ).

Table 3 shows the distribution of scores for the four categories related to the performance 
Mean time and standard error (SE) for timed "repeat chair stands" (seconds), timed "pick up a pen" test (seconds), and handgrip strength $(\mathrm{kg})$ by gender and age groups. SABE, São Paulo, Brazil, 2001.

\begin{tabular}{|c|c|c|c|c|}
\hline \multirow[t]{2}{*}{ Tests } & \multicolumn{4}{|c|}{ Age groups } \\
\hline & $60-69$ & 70-79 & $\geq 80$ & All \\
\hline \multicolumn{5}{|l|}{ Chair stand } \\
\hline Women (972) & $12.48 \pm 0.24^{\star}$ & $14.21 \pm 0.25^{\star}$ & $17.16 \pm 0.48^{*}$ & $14.01 \pm 0.17^{\star \star \star}$ \\
\hline Men (676) & $11.14 \pm 0.29$ & $12.75 \pm 0.27$ & $14.56 \pm 0.39$ & $12.56 \pm 0.18^{\star \star \star}$ \\
\hline \multicolumn{5}{|l|}{ Pick up a pen } \\
\hline Women (979) & $1.92 \pm 0.06^{\star \star}$ & $2.43 \pm 0.19 * \star$ & $3.12 \pm 0.24^{\star \star \star}$ & $2.35 \pm 0.06$ \\
\hline Men (677) & $1.65 \pm 0.06^{\star \star}$ & $1.97 \pm 0.08^{\star \star}$ & $2.95 \pm 0.17^{\star \star \star}$ & $2.07 \pm 0.06$ \\
\hline \multicolumn{5}{|l|}{ Handgrip strength } \\
\hline Women $(1,095)$ & $21.43 \pm 0.25^{\star}$ & $19.03 \pm 0.24^{\star}$ & $14.63 \pm 0.31 *$ & $19.01 \pm 0.17^{\star \star \star}$ \\
\hline Men (756) & $35.04 \pm 0.51$ & $29.59 \pm 0.43$ & $24.82 \pm 0.54$ & $30.28 \pm 0.32^{\star \star \star}$ \\
\hline
\end{tabular}

$\star(p=0.000)$.

$\star \star(p=0.002)$ difference of mean values between the sexes (Student $t$ test).

$\star \star \star ~(p=0.000)$ difference of mean values across age groups (ANOVA).

Table 2

Percentile for those completing the tests (age group and sex): repeat "chair stands" (seconds), timed "pick up a pen" test (seconds), and hand grip strength (kg).

\begin{tabular}{|c|c|c|c|c|c|c|c|c|c|}
\hline \multirow[t]{2}{*}{ Age group } & \multicolumn{4}{|c|}{ Women } & \multicolumn{4}{|c|}{ Men } & \multirow{2}{*}{$\begin{array}{c}\text { All } \\
\geq 60\end{array}$} \\
\hline & $60-69$ & $70-79$ & $\geq 80$ & All & $60-69$ & $70-79$ & $\geq 80$ & All & \\
\hline Chair stand (n) & $(414)$ & $(381)$ & (179) & (974) & $(254)$ & $(268)$ & (156) & (678) & $(1,652)$ \\
\hline 10 & 8.0 & 9.0 & 10.0 & 9.0 & 7.0 & 8.0 & 10.0 & 8.0 & 8.0 \\
\hline 25 & 10.0 & 11.0 & 12.0 & 10.0 & 8.0 & 10.0 & 11.0 & 10.0 & $10.0 *$ \\
\hline 50 & 12.0 & 14.0 & 16.0 & 13.0 & 11.0 & 12.0 & 14.0 & 12.0 & 12.0 \\
\hline 75 & 14.0 & 17.0 & 20.0 & 17.0 & 13.0 & 15.0 & 17.0 & 15.0 & $16.0^{*}$ \\
\hline 90 & 18.0 & 20.0 & 26.0 & 20.5 & 15.0 & 19.0 & 22.0 & 18.0 & 20.0 \\
\hline Pick up a pen (n) & $(417)$ & (389) & $(187)$ & (993) & $(252)$ & $(275)$ & (156) & $(683)$ & $(1,676)$ \\
\hline 10 & 1.0 & 1.0 & 1.0 & 1.0 & 1.0 & 1.0 & 1.0 & 1.0 & 1.0 \\
\hline 25 & 1.0 & 1.0 & 2.0 & 1.0 & 1.0 & 1.0 & 1.0 & 1.0 & 1.0 \\
\hline 50 & 2.0 & 2.0 & 3.0 & 2.0 & 1.0 & 2.0 & 2.0 & 2.0 & 2.0 \\
\hline 75 & 2.0 & 3.0 & 4.0 & 3.0 & 2.0 & 2.0 & 4.0 & 2.0 & 3.0 \\
\hline 90 & 3.0 & 4.0 & 6.0 & 4.0 & 3.0 & 3.0 & 6.0 & 4.0 & 4.0 \\
\hline Handgrip strength (n) & $(435)$ & $(419)$ & $(241)$ & $(1,095)$ & $(264)$ & (299) & (193) & $(756)$ & - \\
\hline 10 & 15.0 & 13.0 & 9.0 & 12.0 & 24.0 & 20.0 & 15.0 & 19.0 & - \\
\hline 25 & 18.0 & 16.0 & 11.0 & $15.0^{*}$ & 30.0 & 25.0 & 20.0 & $24.0^{*}$ & - \\
\hline 50 & 22.0 & 19.0 & 14.0 & 19.0 & 36.0 & 30.0 & 25.0 & 30.0 & - \\
\hline 75 & 25.0 & 22.0 & 17.5 & $23.0^{*}$ & 41.0 & 35.0 & 30.0 & $36.0^{*}$ & - \\
\hline 90 & 28.0 & 25.0 & 20.0 & 26.0 & 45.0 & 39.0 & 34.0 & 41.0 & - \\
\hline
\end{tabular}

* Used to define categories of performance. 
Distribution (\%) of the elderly according to age group, sex, and performance categories on Tests.

SABE, São Paulo, Brazil, 2001.

\begin{tabular}{|c|c|c|c|c|c|c|c|c|}
\hline \multirow[t]{2}{*}{ Tests } & \multicolumn{4}{|c|}{ Women (\%) } & \multicolumn{4}{|c|}{ Men (\%) } \\
\hline & $60-69$ & $70-79$ & $\geq 80$ & $\begin{array}{c}\mathrm{p}<\text { value } \\
\left(\chi^{2}{ }_{6}\right)\end{array}$ & $60-69$ & $70-79$ & $\geq 80$ & $\begin{array}{c}\mathrm{p}<\text { value } \\
\left(\chi^{2}{ }_{6}\right)\end{array}$ \\
\hline Grip strength (n) & $(438)$ & $(425)$ & $(256)$ & & $(266)$ & $(301)$ & $(200)$ & \\
\hline Unable & 0.7 & 1.4 & 5.9 & 0.000 & 0.8 & 0.7 & 3.5 & 0.000 \\
\hline Poor & 12.8 & 24.0 & 54.7 & $(223.948)$ & 10.2 & 23.3 & 47.5 & $(161.383)$ \\
\hline Average & 51.6 & 56.9 & 35.9 & & 45.1 & 59.1 & 43.5 & \\
\hline \multirow[t]{2}{*}{ Good } & 34.3 & 17.6 & 3.5 & & 44.0 & 16.9 & 5.5 & \\
\hline & 100.0 & 100.0 & 100.0 & & 100.0 & 100.0 & 100.0 & \\
\hline Chair stand & $(424)$ & $(401)$ & $(208)$ & & $(261)$ & $(278)$ & $(173)$ & \\
\hline Unable & 2.4 & 5.2 & 14.4 & 0.000 & 2.7 & 4.0 & 10.4 & 0.000 \\
\hline Poor & 13.9 & 24.7 & 40.9 & $(125.628)$ & 6.5 & 14.0 & 23.1 & (65.904) \\
\hline Average & 48.8 & 49.4 & 35.1 & & 42.5 & 50.7 & 48.6 & \\
\hline \multirow[t]{2}{*}{ Good } & 34.9 & 20.7 & 9.6 & & 48.3 & 31.3 & 17.9 & \\
\hline & 100.0 & 100.0 & 100.0 & & 100.0 & 100.0 & 100.0 & \\
\hline Pick up a pen & $(426)$ & $(403)$ & (209) & & (259) & $(284)$ & $(169)$ & \\
\hline Unable & 2.8 & 5.0 & 12.9 & 0.000 & 3.1 & 4.6 & 8.3 & 0.000 \\
\hline Poor & 0.7 & 3.2 & 4.8 & (91.045) & 0.4 & 1.1 & 5.9 & $(79.567)$ \\
\hline Average & 17.1 & 28.0 & 38.8 & & 11.2 & 17.6 & 37.3 & \\
\hline \multirow[t]{2}{*}{ Good } & 79.3 & 63.8 & 43.5 & & 85.3 & 76.8 & 48.5 & \\
\hline & 100.0 & 100.0 & 100.0 & & 100.0 & 100.0 & 100.0 & \\
\hline Balance & $(433)$ & $(418)$ & $(225)$ & & $(263)$ & $(291)$ & $(182)$ & \\
\hline Unable & 2.3 & 4.1 & 11.6 & 0.000 & 2.7 & 3.8 & 9.3 & 0.000 \\
\hline Poor & 11.3 & 28.7 & 51.1 & $(287.147)$ & 8.4 & 20.6 & 33.0 & (115.557) \\
\hline Average & 16.6 & 34.0 & 28.9 & & 15.6 & 28.5 & 34.1 & \\
\hline \multirow[t]{2}{*}{ Good } & 69.7 & 33.3 & 8.4 & & 73.4 & 47.1 & 23.6 & \\
\hline & 100.0 & 100.0 & 100.0 & & 100.0 & 100.0 & 100.0 & \\
\hline
\end{tabular}

on each task (handgrip, repeat "chair stand", "pick up a pen", and balance) by age groups for women and men. With increasing age, both sexes showed a reduction $(p=0.000)$ in the proportion of individuals with better results for each test. The proportion of individuals physically unable to perform the tasks increased with age, and women were more likely not to perform the tests (unable). Men (in all age groups) had proportionately better scores than women in the four tests.

The proportion for performance was specific to each test, and the "pick up a pen" test showed a higher prevalence of women and men (Table 1), in all age groups, with better scores than other tests. This test also showed a greater percentage of people unable to complete the task, in all age groups and both sexes.

Scores on the three performance tasks were significantly correlated. Spearman correlation coefficients for the categorical scores (for women and men, respectively) were: (a) "chair stand" $\mathrm{x}$ "pick up a pen", 0.44 and 0.49; (b) "chair stand" $\mathrm{x}$ balance, 0.41 and 0.41 ; (c) "chair stand" $\mathrm{x}$ grip strength, 0.33 and 0.34 ; (d) balance $\mathrm{x}$ "pick up a pen”, 0.42 and 0.45 ; (e) balance $\mathrm{x}$ grip strength, 0.38 and 0.35 ; (f) "pick up a pen" $x$ grip strength, 0.26 and 0.34 (all significant at $\mathrm{p}<0.01$ ).

\section{Discussion}

This is the first household-based population study in Brazilian elderly to verify functional limitations using physical performance tests. The study included a representative sample of the elderly population, which suggests that the findings may be extrapolated to apply to the elderly of São Paulo city and, in the absence of reference data for the elderly of the country as 
a whole, may also be taken as a reference for the Brazilian elderly in general.

Since the data are part of an international multicenter study, they may be compared to those from the other countries in Latin America and the Caribbean participating in the SABE survey.

Upper body strength was assessed by handgrip, and lower extremity functions by three independent measures: timed repetitive "chair stands", a task used to assess lower body strength 7; timed "pick up a pen", in which the ability to bend down to the floor correlates with hip flexion 8; and standing balance: tasks that are involved in performing daily activities. These tests are part of some batteries that have been developed to assess functional limitations in the elderly: Physical Performance Test 6; Performance Battery - EPESE battery 9; and Functional Fitness Test 4.

Performance-based measures can offer advantages over self-reports in terms of validity, reproducibility, sensitivity to changes, cultural and educational influences, applicability in population studies, and ability to represent high levels of physical and/or functional capability. Moreover, they provide useful preliminary knowledge about healthy elderly subjects and risk or progression to disability in non-disabled older subjects. They are an ideal way of targeting a subset of the population for clinical trials on disability prevention 3 .

Data on the elderly in São Paulo showed that the timed "pick up a pen" test had a higher percentage of men and women with better results in all age groups. Although the number of elderly that were unable to do the lower body function tests was not very different, it was greater in the timed repetitive "chair stands".

The difference between tests relating to the prevalence of better results can be partially explained by the difficulty in choosing measures that are applicable for both active and frail elderly 10 . In the case of population studies, it is also difficult to choose tests that do not require expensive instruments, are low-cost and easily applied by the interviewers, and are capable of evaluating their proposed targets.

Some measures, such as the one-leg stand (balance), can be difficult for more frail individuals, but the repetitive "chair stand" can be easy for very active subjects 10 . Meanwhile, the "pick up a pen" test proved to be easier for the elderly of all age groups and both sexes in São Paulo, as compared to performance on other tests.

However, the handgrip strength test is considered appropriate for all individuals, because it does not require bearing body weight and can be done by everyone, including those who cannot walk. However, most studies use a different protocol from that of the SABE survey. This test is usually taken with the person standing, with arms loose next to the body, for which there are protocol categorizations that allow comparison of the values 11 .

The results showed that there is a reduction, with increasing age, in the proportion of individuals with better scores on the tests. This reduction was greater in the oldest age group. It has also been shown that women in all age groups had weak performance as compared to men. Results from this analysis are consistent with other studies $2,4,7,9,12$, suggesting that older individuals and women suffer greater physical limitation.

Despite the consistency with other studies, there are some factors that make the comparison between studies quite difficult: use of different test methods and/or protocols 4; differences between the age groups evaluated 7,9; gender and number of individuals from the study population; sample selection criteria 9,12; and the way results are presented 2,9,12.

In Ferrucci et al. 12, the population consisted of elderly individuals of both sexes ( $\geq 71$ years) from a number of American cities $(n=3,381)$. The sample 12 was consisted of those who, in previous interviews, reported no need of help to walk a quarter mile or climb stairs. Moreover, the results for the three performance tests used (balance; timed repeat chair stand; timed 2.4-m walk) were added and presented in a single score.

When compared to data from the third National Health and Nutritional Survey (NHANES III) 2 , involving 5,304 individuals ( $\geq 60$ years), the mean time $( \pm$ SE) in seconds spent by elderly men of São Paulo to perform the "chair stand" test was less for the 60-69 (11.14 \pm 0.29 vs. $12.65 \pm$ $0.24)$ and $70-79$ age groups $(12.75 \pm 0.27 v s$. $13.35 \pm 0.29)$, and was the same for the oldest age group ( $14.56 \pm 0.39 v s .14 .70 \pm 0.25)$; while elderly women $(n=2,760)$ in São Paulo from the 60-69 age group showed better performance on this test, compared to the Americans: $12.48 \pm$ $0.24 v s .13 .22 \pm 0.22,14.21 \pm 0.25 v s .14 .19 \pm 0.29$, and $17.16 \pm 0.48 v s .16 .58 \pm 0.30$ for the $60-69$, $70-79$, and $\geq 80$ age groups, respectively.

The difference, between studies, in the percentage of seniors who were physically unable to perform the tests is extremely evident. In the NHANES III data $2,5.6 \%$ and $9.0 \%$ of the male and female elderly, respectively, were physically unable to perform the timed "chair stand", while the frequency for the São Paulo individuals was $5.1 \%$ and $5.9 \%$ for men and women, respectively (data not shown). 
In the standing balance test used in NHANES III 2 (full tandem stand), the proportion of elderly who were unable to maintain the position for 10 seconds was $26.0 \%$ and $32.0 \%$, for men and women respectively, against $18.1 \%$ (men) and $24.6 \%$ (women) of the elderly evaluated in the current study (Table 4). These data suggest that, concerning this balance measure (full tandem stand), the elderly of São Paulo show better performance than the Americans.

The handgrip strength of men in this study can be compared to that of 3,640 elderly Japanese-American men ( $\geq 70$ years), in a study that used the same methodology 7 . The values observed by Young et al. 7 were: $32.6 \pm 6.5 \mathrm{~kg}(70-74$ years); $29.8 \pm 6.4 \mathrm{~kg}$ (75-79 years); $27.3 \pm 6.3 \mathrm{~kg}$ (80-84 years); and $22.7 \pm 7.0 \mathrm{~kg}$ ( 85 and older), which were higher than those obtained in the São Paulo elderly (Table 1), suggesting that the latter individuals are weaker.

The differences observed among the several studies and the present research concerning the performance and prevalence of inability to perform the tests may be due to the selection and/or exclusion criteria for the elderly, the number of participating subjects, differences in body composition, social and economic conditions, and individual lifestyle, among other environmental and genetic factors.

As for the "pick up a pen" test, in the surveys that have used it, the results were presented with those from other tests and combined in one score. They showed that individuals with a low rating, along with other motor performance measures, had a risk of having functional dependence 13 .

Several factors have been reported as related to reduced physical function or increased functional limitation, which is observed in aging. They include chronic diseases, reduced physical activity, and the normal physiological changes in aging, such as decreased muscle mass (both in quantity and quality) and decreased hormone levels, among numerous others 1,14.
Differences in physical capacity between the sexes are well-known, and an explanation has been given to attempt to justify them. Several studies have identified female gender as an independent risk factor for functional reduction: because women have a longer life expectancy, they can suffer more readily from a larger number (or different kinds) of chronic diseases, resulting in functional limitations and disability 2,15 . For São Paulo's elderly, evaluated in the SABE survey $(2,143$ people), $22.0 \%$ and $18.0 \%$ of the female and male samples, respectively, reported three or more diseases, while $20.0 \%$ of women and $28.0 \%$ of men reported not having any kind of chronic disease 16.

Another explanation concerns socioeconomic level, which can limit access to healthcare and health-related behavior 2. Women outnumber men among both the elderly and chronic disease patients, and problems related to poverty in old age affect females intensely. Women also have less mean schooling and lower income levels. In São Paulo 16, the prevalence of elderly with no schooling at all was higher among women $(26.0 \%)$, compared to men aged 60 and over $(22.8 \%)$.

Nutritional status and/or body composition can be related to differences between genders as well as among age groups, in the performance of the tests. Obese elderly can become incapacitated due to the greater frequency of chronic diseases 15 that can lead to loss of mobility, even though epidemiological studies on the impact of these diseases on lower extremity function are not widely available in literature. Among São Paulo's senior citizens, obesity is more frequent in women and underweight in men 17 , over all the age groups 18 .

Some notes have been on the results: (a) prevalence relating to performances differed from one test to another; (b) with increasing age, both genders presented a reduced percentage of individuals with better results in all tests; and (c) on every test, men had a higher

Distribution (\%) of individuals, according to sex, for each measurement of the balance test.

\begin{tabular}{|c|c|c|c|c|c|c|c|c|c|c|}
\hline & \multicolumn{2}{|c|}{ All elderly } & \multicolumn{2}{|c|}{$1 \mathrm{st}$} & \multicolumn{2}{|c|}{ 2nd } & \multicolumn{2}{|c|}{$3 r d$} & \multicolumn{2}{|c|}{4 th } \\
\hline & $\begin{array}{c}\text { Women } \\
(1,076)\end{array}$ & $\begin{array}{l}\text { Men } \\
(736)\end{array}$ & $\begin{array}{c}\text { Women } \\
(1,031)\end{array}$ & $\begin{array}{l}\text { Men } \\
(707)\end{array}$ & $\begin{array}{c}\text { Women } \\
(1,004)\end{array}$ & $\begin{array}{l}\text { Men } \\
(792)\end{array}$ & $\begin{array}{c}\text { Women } \\
\text { (733) }\end{array}$ & $\begin{array}{l}\text { Men } \\
(638)\end{array}$ & $\begin{array}{c}\text { Women } \\
\text { (721) }\end{array}$ & $\begin{array}{l}\text { Men } \\
(540)\end{array}$ \\
\hline Unable & 4.2 & 3.9 & $0.8(0.7)^{\star}$ & $0.8(0.8)^{\star}$ & $26.4(24.6)^{\star}$ & $19.2(18.1)^{\star}$ & $50.6(34.5)^{\star}$ & $42.2(31.4)^{\star}$ & $53.0(35.5)^{\star}$ & $44.6(32.7)^{\star}$ \\
\hline Able & 95.8 & 96.1 & $99.2(95.9)^{\star}$ & $99.2(95.2)^{\star}$ & $73.6(68.7)^{*}$ & $80.8(75.9)^{\star}$ & $49.4(33.6)^{\star}$ & $57.8(43.1)^{\star}$ & $47.0(31.5)^{\star}$ & $55.4(46.1)^{*}$ \\
\hline
\end{tabular}

* Percentage relative to total elderly. 
proportion of individuals with better results, compared to women from the same age group.

This study presents the limitations inherent to cross-sectional studies such as the cohort effect, which interferes in the interpretation of age differences and alterations due to aging. Additionally, the study does not permit the assessment of individual changes in physical performance. The results represent a moment in the lives of these individuals residing in the city of São Paulo, but without identifying the facts that led to the conclusion. Various events may have taken place throughout the lives of several seniors, even though by the time of the study they had similar performance attributes. Environmental and behavioral factors, which were not evaluated in this study, can also be related to test performance.

\section{Resumo}

Em amostra representativa de idosos residentes no Município de São Paulo, Brasil, foram utilizados testes de desempenho motor (TDM) com objetivo de verificar a proporção de indivíduos, de acordo com sexo e grupo etário, quanto à limitação funcional. Trata-se de estudo epidemiológico transversal, de base populacional e domiciliar, parte de pesquisa multicêntrica (SABE), coordenada pela Organização Pan-Americana da Saúde. A SABE abrangeu 2.143 idosos ( $\geq 60$ anos), de ambos os sexos, no período de janeiro/2000 a março/ 2001; sendo que $1.894(88,4 \%)$ participaram deste estudo. Os seguintes TDM foram utilizados: força de preensão manual; "sentar e levantar" e "agachar e pegar uma caneta" (avaliados por tempo) e; teste de equilíbrio estático. A prevalência quanto ao desempenho (qui-quadrado) foi específica para sexo, grupo etário e teste utilizado. O percentual de homens e mulheres com melhor escore foi menor $(p=0,000)$ nos grupos etários mais avançados. Quando comparados às mulheres, os homens, em todos os grupos etários, apresentaram melhores resultados nos testes. O presente estudo fornece evidências de que a limitação funcional é mais freqüente no sexo feminino e nos indivíduos mais idosos.

Saúde do Idoso; Envelhecimento; Força da Mão; Estudos de Tempo e Movimento
The data provide information on the prevalence of functional limitation in these individuals, according to performance on the handgrip strength and lower extremity function tests. The data also support the planning of measures for the prevention or treatment of functional limitation in the elderly. Furthermore, in the absence of data related to Brazilian seniors, such information can be useful for comparison and interpretation of functional performance by the elderly, both in medical practice and epidemiological studies.

Other studies are necessary to evaluate the association between motor performance tests and: anthropometrical indicators of nutritional status and body composition; other health indicators such as self-perception measures concerning functional status; chronic diseases; and socioeconomic and cultural conditions. Longitudinal studies are also recommended.

\section{Contributors}

A. R. Barbosa, J. M. P. Souza, M. L. Lebrão, R. Laurenti, and M. F. N. Marucci contributed to the design, planning, and/or data interpretation; A. R. Barbosa, J. M. P. Souza, and M. F. N. Marucci contributed to the drafting and critical review of the content; A. R. Barbosa and M. F. N. Marucci participated in the approval of the paper's final version.

\section{Acknowledgments}

In Brazil, the SABE survey was supported by the São Paulo State Research Foundation (FAPESP), and this study was supported in part by an educational grant from the Coordinating Body for Training University Level Personnel (CAPES). 


\section{References}

1. Samson MM, Meeuwsen IBAE, Crowe A, Dessens JAG, Duursma SA, Verhaar HJJ. Relationships between physical performance measures, age, height and body weight in healthy adults. Age Ageing 2000; 29:235-42.

2. Ostchega Y, Harris TB, Hirsch R, Parsons VL, Kington R, Katzoff M. Reliability and prevalence of physical performance examination assessing mobility and balance in older persons in the US: data from the third National and Nutrition Examination Survey. J Am Geriatr Soc 2000; 48:1136-41.

3. Guralnick JM, Ferruci L. Assessing the building blocks of function utilizing measures of functional limitation. Am J Prev Med 2003; 25:112-21.

4. Rikli RE, Jones J. Functional fitness normative scores for community-residing older adults, ages 60-94. J Aging Physic Act 1999; 7:162-81.

5. Silva NN. Amostragem. In: Lebrão ML, Duarte YAO, organizadores. O Projeto SABE no município de São Paulo: uma abordagem inicial. Brasília: Organização Pan-Americana da Saúde; 2003. p. 45-57.

6. Reuben DB, Siu AL. An objective measure of physical function of elderly outpatients - The Physical Performance Test. J Am Geriatr Soc 1990; 38:1105-12.

7. Young DR, Masaki KH, Curb JD. Associations of physical activity with performance-based and self-reported physical functioning in older men: The Honolulu Heart Program. J Am Geriatr Soc 1995; 43:845-54.

8. Badley EM, Wagstaff S, Wood PHN. Measures of functional ability (disability) in arthritis in relation to impairment of range of joint movement. Ann Rheum Dis 1984; 43:563-9.

9. Guralnick JM, Simonsck EM, Ferrucci L, Glynn RJ, Berkman LF, Blazer DG, et al. A short physical performance battery assessing lower extremity function: association with self-reported disability and prediction of mortality and nursing home admission. J Gerontol 1994; 49:M85-94.

10. Harris TB. Body composition in studies of aging: new opportunities to better understand health risks associated with weight. Am J Epidemiol 2002; 156:122-4.
11. American College of Sports Medicine. ACSM's guidelines for exercise testing and prescription. Baltimore: Williams \& Wilkins; 1995.

12. Ferrucci L, Pennix BWJH, Leveille SG, Corti MC, Pahor M, Wallace R. Characteristics of disabled older persons who perform poorly in objective tests of lower extremity function. J Am Geriatr Soc 2000; 48:1102-10.

13. Gill TM, Williams CS, Tinetti ME. Assessing risk for the onset of functional dependence among older adults: the role of physical performance. J Am Geriatr Soc 1995; 43:603-9.

14. Landers KA, Hunter GR, Wetzstein CJ, Bamman MM, Weinsier RL. The interrelationship among muscle mass, strength and ability to perform physical tasks of daily living in younger and older women. J Gerontol A Biol Sci Med Sci 2001; 56:B443-8.

15. Friedmann JM, Elasy T, Jensen GL. The relationship between body mass index and self-reported functional limitation among older adults: a gender difference. J Am Geriatr Soc 2001; 9:398-403.

16. Peláez M, Palloni A, Albala JC, Ham-Chande R, Hennis A, Lebrão ML, et al. Survey on aging, health and wellbeing, 2000. Washington DC: Pan American Health Organization; 2003.

17. Marucci MFN, Barbosa AR. Estado nutricional e capacidade física de idosos residentes no município de São Paulo. In: Lebrão ML, Duarte YAO, organizadores. O Projeto SABE no município de São Paulo: uma abordagem inicial. Brasília: Organização Pan-Americana da Saúde; 2003. p. 95-117.

18. Barbosa AR, Souza JMP, Lebrão ML, Laurenti R, Marucci MFN. Anthropometry of the elderly living in São Paulo, Brazil. Cad Saúde Pública; in press.

Submitted on $14 / \operatorname{Jan} / 2004$

Final version resubmitted on 10/Sep/2004

Approved on 15/Sep/2004 